\title{
Küiltüir Ekonomisi Açısından İzmir'in Akdeniz'deki Yeri
}

\author{
Şebnem Gökçen Dündar*
}

\section{Özet}

Yeni zamanlar ile birlikte değişen koşullar kültür ve yaratıcılık üzerinden kentsel ekonomileri ve coğrafyaları dönüştürmekte, kültür bölge ekonomisine yaptığı katkıyla önemli bir yerel ekonomik girdi teşkil etmektedir. Bu ezber bozan gelişmeler dünyayla birlikte kuşkusuz Akdeniz havzasında da gözlenmekte, bu yönde çeşitli örgütlenmelerin yanı sıra kültür ekonomisinin nasıl kümelendiği ölçümlenmeye çalışılmakta, bu süreci kültür politika ve stratejilerinin oluşumu izlemektedir. Bu çalışmanın amacı, dünya ölçeğinden başlayarak Akdeniz havzası içindeki kültür ekonomisinin kentler ve bölgeler üzerindeki yansımalarının tespitinde dikkat edilmesi gereken hususları irdelemek ve İzmir'de kültür ekonomisi kapsamındaki gelişmeleri kentin Akdeniz kentleri ağı içerisindeki konumu itibariyle tartışmaktır. Bu kapsamdaki tartışmalar, kültür ekonomisi açısından Akdeniz kentlerine yönelik spesifik çalışmalar için bir başlangıç perspektifi oluşturma amacı taşımaktadır.

Anahtar sözcükler: Kültür ve yaratıcı endüstriler, kültür ekonomisi, sektörel ve mekânsal kümelenme, Akdeniz havzası, İzmir

\begin{abstract}
With the impact of changing circumstances of the new times, the urban economies and geographies go under such transformation through culture and creativity that culture now is accepted as an important local economic input within the overall regional economies. These breakthrough developments are observed throughout the world, undoubtedly including the Mediterranean basin, and in addition to various ways of getting organized, there are also cultural compendium studies conducted to measure how cultural economy is clustered and how due policies and strategies of culture are formulated. This study intends to scrutinize the points that should be taken into consideration while spotting the effects of cultural economy on cities and regions in the world and the Mediterranean basin. The discussion then focuses on the recent developments in cultural economy of Izmir from the perspective of city's position within the network of Mediterranean cities. The study aims to provide an initial perspective for other specific studies that may delve further into deciphering the current state of cultural economy in Mediterranean cities.
\end{abstract}

Keywords: Cultural and creative industries, cultural economy, sectoral and spatial clustering, Mediterranean basin, Izmir

* Dokuz Eylül Üniversitesi, Şehir ve Bölge Planlama Bölümü 
Kültür alanındaki çalışmaların kültür endüstrileriveyaratıcı endüstriler adını alarak kentlerin yeni ekonomik hedeflerini belirleyici olmaya başladığı 1970’lerden bu yana, "kültür ekonomisi” kavramı da daha sıklıkla kullanılır oldu. Kültürün endüstrileşerek yükselişinin günümüzde geldiği nokta kalkınmanın temel araçlarından biri olarak kabul edildiği ve buna yönelik politikaların oluşturulduğu ve uygulamaya konduğu örneklerin de artışı ile birlikte tartışılıyor. Kültür ve yaratıcı endüstrilerin bölge ekonomisi üzerinde doğrudan ve kayda değer katkılar koyabildiği ve önemli ekonomik girdi yarattığı yönündeki genel bulguların yanı sıra, kültürel altyapının geliştirilmesi ve kültürel çeşitliliğin korunması anlamında da önemli rol oynadığı açıktır. Farklı kentlere, farklı ülkelere ve coğrafyalara ilişkin bu anlamda sayısız çalışmadan bahsedilebilir. Ancak Akdeniz havzası bütünlüğü içerisinde kültür ekonomisi coğrafyasına bakan ve Akdeniz kentlerinin kültür ekonomisi açısından nasıl irdelenebileceğini sorgulayan çalışmaların oldukça kısıtlı olduğu söylenebilecektir. Akdeniz kentler ağının varlığı ise kuşkusuz bu tür bir sorgulamanın önemini daha da artırmaktadır.

Bu çalışmada, ilk olarak yeni zamanlar ile birlikte değişen koşulların kültür ve yaratıcılık üzerinden kentsel ekonomileri ve coğrafyaları nasıl dönüştürdüğüne ilişkin bir bakış açısı sunulacak, sonrasında bu bakışın dünya ölçeğinden başlayarak Akdeniz havzasına yönelen yansımaları deşifre edilmeye çalışılacaktır. Bu doğrultuda İzmir'e ilişkin değerlendirmeler ise kuşkusuz kentin Akdeniz kentleri ağı içerisindeki konumundan bağımsız tartışılamaz. Söz konusu konumun tam olarak tespiti ise çok kapsamlı ve kıyaslamalı analitik çalışmalar yapılmasını gerekli kılmaktadır. Bu çalışma, esas itibariyle Akdeniz havzasına kültür ekonomisi açısından nasıl bakılması gerektiğine ilişkin tespitleri odağa alırken, Akdeniz kentlerine yönelik spesifik çalışmalar için bir başlangıç perspektifi oluşturma amacı taşımaktadır.

\section{Yeni Zamanların Ezber Bozan Gelişmelerinden Kültür Ekonomisine Bakış}

Küresel çağda kültür ve yaratıcılığın sektörel gelişimini "ezber-bozucu" olarak nitelendirilebilecek bir dizi değişim üzerinden ele almak mümkündür. Bu perspektif, bir yandan kentlerin içinde bulundukları koşullara bir nebze farklı bir gözden bakmayı sağlarken, diğer yandan değişen koşullara adaptasyon sürecinin her ayrı kent deneyiminde nasıl farklılaşabileceğine dair ipuçlarını da verebilecektir. Kuşkusuz, kültür ve kalkınma arasındaki ilişkinin kurulmasında kentlere verilebilecek tek bir reçete yoktur. Ancak, bir vizyon dahilinde geleceğe atılacak her adım için farkında olunması gereken koşullar, kentlerin kültür ekonomisi ile ilişkili kalkınma hedeflerinin gerçekleşmesini kolaylaştırabilir.

Bu perspektiften ele alındığında, kentler, kültür ve kalkınma arasındaki ilişkide ezber bozan hususlardan ilki kültür politikalarındaki paradigma değissimidir. Avrupa kıtasındaki kültür politikalarına yönelik 
olarak CIRCLE, UNESCO ve ERICArts gibi kuruluşlarca yürütülen dokuz ayrı analitik çalışmada varılan temel sonuç, ekonomik ve sosyal kalkınmaya katkı sağlayan politikalar ile geleneksel anlamda kültür ve sanatın gelişimine yönelik politikalar arasında ancak bir denge sağlandığı takdirde etkin kültür politikalardan bahsedilebileceği olmuştur. ${ }^{1}$ Bir başka ifadeyle, kültür politikalarının "kültür ekonomisi” ile birlikte ele alınmaya başlaması ve kültür ile yaratıcılığın ekonomik gelişim üzerindeki etkisinin kentlerin geleceğini belirleyici olması hususları artık yaygın olarak kabul görmekte ve bu yönde önemli adımlar atılmaktadır. Kültür endüstrisi alanına kalkınma sorunsalının yeni parametrelerinden biri olarak atfedilen önemi ve artan "tanınırlığı", UNESCO, UNCTAD gibi uluslararası örgütler ile Avrupa Konseyi, AB ve Avrupa İstatistik Ofisi EUROSTAT gibi uluslarüstü organizasyonların bu konulara temas eden istatistikleri, raporları ve çerçeve politikaları ile şekillenmeye ve yeni uluslararası örgütlenme biçimlerine ve bu alanda yeşeren uluslararası ağların oluşumuna olanak tanımaktadır. ${ }^{2}$

Ezber bozan bir başka husus ise, kentsel coğrafyalarda kültür ekonomisi anlamındaki hareketlenmeyi sağlayan "beşeri sermaye"nin eğilimlerine yöneliktir. Tarih boyunca iktisatçıların ve coğrafyacıların gözlem ve araştırma yaptığı tüm alanlarda temel çıkış "bölge odaklı ekonomik gelişim” olmuştur. Belirli sektörlerin coğrafi kümelenmesi ve endüstriyel bölgelerin oluşumu mekânın etkisini vurgulayan görüşlere örnek verilebilir. İktisat ve coğrafyada önceden hâkim olan yaklaşımlarda işletmelerin yer seçiminin beraberinde işgücünü o bölgeye çektiği kabul edilmiştir. Buna göre, bir bölgede sanayi ve ticaret varsa orada beşeri sermaye toplanma eğiliminde olmuş; antik Mezopotamya'dan günümüz modern kentlerinin oluşumuna kadar bu ezber bozulmamıştır. ${ }^{3}$ Oysa bugün geldiğimiz noktada, Richard Florida'nın "yaratıcı sınıf” olarak adlandırdığı beşeri sermayenin bölgesel kalkınmayı yönlendirici olduğu tespiti önemlidir. ${ }^{4}$ Bu tespite temellenen yaratıcı sınıf teorisine göre, bölgeler ve şehirler yaratıcı sınıfın değerlerine, yaşam tarzlarına ve beklentilerine uygunsa yaratıcı sınıf o bölgeye yönelmektedir. Teorinin temelinde nitelikli işgücünün çalışacakları işyerlerini değil, belirli özelliklere sahip mekân ve hayat tarzını seçmekte olmaları yatar. Yaratıcı sınıf mobildir ve nerede, hangi şehirde yer seçer ve o şehirde kendi mesleklerine uygun işleri tercih ederse ve o meslek alanında çalışanlar zaman içerisinde o şehirde kümelenirse, o şehirde beraberinde refah

\footnotetext{
1 Ritva Mitchell, "Nordic and European cultural policies", The Nordic Cultural Model içinde, der. P. Duelund (Kopenhag: Nordic Cultural Institute, 2003), 459.

2 Şebnem Gökçen Dündar, "Kültür Endüstrisi ve Bölgesel Kalkınma”, Bölgesel Kalkınmada Yeni Trendler içinde, der. Z. Mızrak ve B. Mercan (Konya: Çizgi Kitabevi, 2016), 249.

3 Richard Florida, "Cities and the Creative Class", City and Community 2: 1 (2003), 4, erişim tarihi 11 Ekim 2016, http://isites.harvard.edu/fs/docs/icb.topic233886.files/April_8/ Florida_Cities.pdf.

4. Richard Florida, The Rise of the Creative Class (New York, NY: Basic Books, 2002); Florida, "Cities and the Creative Class".
} 
artışı gerçekleşmektedir. Böylelikle, mekânların niteliğinin yaratıcı sınıf tarafından belirlendiği bu yeni coğrafya rejiminde, yaratıcı sermaye aynı zamanda iktisadi büyümenin de belirleyicisi olmaktadır.

Bir diğer ezber ise coğrafya ile ekonomi arasındaki ilişkiye ilişkin olarak tartışılabilir. Üçüncü sanayi devrimi ile birlikte gözlendiği ve kuramsallaştırıldığı üzere, zamanın ve mekânın sıkıștığı küresel çağda, giderek coğrafyanın ve mekânın öneminin azaldığı iddia edilir ve "Coğrafyanın Ölümü” bir modern mit olarak nitelendirilir. Nitekim ekonomik peyzaj mekândan büyük ölçüde bağımsızlaşmakta, yeni ekonomiyi oluşturan iletişim teknolojilerindeki değişim ve gelişimlerle birlikte, ekonomik ilişkiler fiziki coğrafya sınırlarını aşarak sanal akışlarla tüm dünya coğrafyasında bambaşka bir ağ içinde yönlendirilebilmektedir. Oysa, tam da aksi yönde gelişmelerle, son yıllarda sadece yaratıcı sınıfın değil, ekonomik büyümeyi tetikleyen bilgi-temelli, yüksek-teknolojili ve yaratıcı-içerikli endüstrilerin de belirli coğrafyalarda kümelendiği açıktır. "Yer" olgusunun daha önce hiç olmadığı kadar vurgulanması boşuna değildir. Jane Jacobs'ın ilk kez 196o'lı yıllarda dile getirdiğinden bu yana kentler giderek yaratıcılığın, yeniliğin ve yeni endüstrilerin kuluçka mekânları olarak isslev görürken, ${ }^{5}$ kümelenme gösteren sektörler de beraberinde soyut bir mekândan ziyade, yerin ekonomik yaşam için önemine işaret etmektedir. Kentler, bir yandan bilgi çağında kültür ve yaratıcı endüstrileri odağa alan rekabet edebilirlik stratejileri geliştirirken, diğer yandan kendilerine esaslı bir çeki düzen verme hedefi peşinde birer "dönüşüm” nesnesi haline gelmektedir. İster kültür-eksenli dönüşüm olsun, ister karma-kullanım ya da etkinlik-eksenli dönüşüm, "kentsel dönüşüm”ün tartışılmadığı ve/veya uygulanmadığı kent sayısı giderek azalmaktadır.

Tüm bu ezber bozan gelişmelerin içerisinde kültürün endüstrileşmesine yönelik olarak Adorno ve Horkheimer'ın 1970’li yıllardaki eleştirilerine değinmeye gerek kalmaz. "Kültür endüstrisi" kavramının yaratıcısı Adorno ve Horkheimer' $n^{6}$ kültür ve sanatın biricikliğinin seri üretime konu edilemeyeceği yönünde önermelerinin üzerinden çok sayıda araştırma, çok sayıda kent deneyimi ve çok sayıda akademik ve bilimsel çalışma geçmiş ve bugünün kültür ekonomisi yazınını ve pratiğini oluşturan bir çerçeveyi yıllar içinde adeta katlanarak oluşturmuş durumdadır. Sonuçta, kültür ekonomisi yeni bir vizyon ve yeni politika arayışındaki günümüz kentlerinin sırtını çeviremeyeceği bir çerçeve sunmaktadır.

Kentlerin küresel çağda içerisinde konumlandıkları noktaya kültür ekonomisi çerçevesinden bakmaları ise, kentsel rekabet koşullarında giderek zaruri hale gelmiştir. Durduğumuz spesifik noktayı anlamak ve geleceğe taşımak için önce o noktanın bağlamsal bütünlük içinde olduğu çevresini, sonrasında ise o çevrenin de bağımlı olduğu daha üst

5 Florida, "Cities and the Creative Class".

6 Bkz. Theodor W. Adorno, Kültür Endüstrisi, Kültür Yönetimi, çev. M. Tüzel, N. Ülner ve E. Gen (İstanbul: İletişim Yayınları, 2014). 
çerçeveyi kavramak gerekecektir. Daha açık ifade etmek gerekirse, durduğumuz nokta İzmir ise, İzmir'in coğrafi, kültürel ve ekonomik olarak parçası olduğu Akdeniz havzasına bakmak zorunluluk içerir. Ancak hiç kuşku yoktur ki, yeni zamanların dinamikleri ve ezber bozan değişimler ilk önce küresel ölçekten Akdeniz havzasına bakarak var olan gelişmeleri algılamayı gerektirecektir. Bu yazıdaki gibi kısa bir bakışta kültür ekonomisinin sergilediği küresel/yerel tabloyu kapsamlı bir şekilde ayrıntılandırmak mümkün olmasa bile, böyle bir bakış açısının beraberinde getireceği potansiyellerin varlığının tartışılması son derece önemli bir başlangıç noktası teşkil eder.

\section{Dünya Ölçeğinden Akdeniz'e Kültür ve Yaratıcı Endüstriler}

Kültür ekonomisi çatısı altında medyadan, görsel sanatlara, mimariden basın-yayına çok sayıda sektör için ortaya konulan istatistiklerin söylediği en önemli husus, son yıllarda gelişmiş ülkelerdeki ekonomik durgunluğa rağmen, kültür ekonomisinin dünya ölçeğinde her kıtada ve özellikle de güney kürede, kayda değer bir büyüme göstermesidir.? Avrupa kentleri örneğinde en yüksek refah seviyesine sahip kentlerin kültür ve yaratıcı endüstrilerin en fazla kümelendiği kentler olduğu8 yönündeki tespitlerin yanı sıra, kültür ve yaratıcı sektörlerin ekonomik kriz zamanlarından görece olarak daha az etkilendikleri öne sürülmektedir. ${ }^{9}$ İlk olarak 2008 yılında, sonrasında 2010 yılında hazırlanan Yaratıcı Ekonomi raporlarının sunduğu istatistiklerle kıyaslandığında, 2013 tarihli Yaratıcı Ekonomi raporunda giderek daha fazla sayıda ülkenin gayrisafi milli hâsılayı artıran kültür ekonomisi yatırımlarına yöneldiği tespit edilmektedir. Daha yakın tarihli bir araştırmaya göre ise günümüzde dünyada kültür ve yaratıcı endüstrilerden elde edilen gelir 2.250 milyar Amerikan doları olarak kayda geçmektedir. Yine tüm dünya ölçeğinde kültürel ve yaratıcı sektörlerde çalışan sayısının tüm dünyanın aktif nüfusunun \%1'ini oluşturacak şekilde 29,5 milyona ulaştığı belirtilmiştir. ${ }^{10}$ Bu rakamları oluşturan alt sektörlerin en başında televizyon (477 milyar dolar), görsel sanatlar (391 milyar dolar) ve basın-yayın (gazete ve dergiler - 354 milyar dolar) alanları gelmekte; en çok istihdam üre-

7 United Nations/UNDP/UNESCO, Creative Economy Report 2013 Special Edition: Widening Local Development Pathways (New York, NY: United Nations Development Program, 2013), erişim tarihi 9 Ekim 2016, http://www.unesco.org/culture/pdf/creativeeconomy-report-2013.pdf.

8 Dominic Power ve Tobias Nielsén, Priority Sector Report: Creative and Cultural Industries. Preliminary Version (Brüksel: European Cluster Observatory, 2010); Dominic Power, Priority Sector Report: Creative and Cultural Industries (Lüksemburg: European Commission, European Cluster Observatory, 2011).

9 Todd Gabe, Richard Florida ve Charlotta Mellander, “The Creative Class and the Crisis", Cambridge Journal of Regions, Economy, and Society 6 (2013), 37-53.

10 UNESCO/EY/CISAC, Cultural Times: The First Global Map of Cultural and Creative Industries (EY, 2015), erişim tarihi 11 Ekim 2016, http://www.ey.com/Publication/ vwLUAssets/ey-cultural-times-2015/\$FILE/ey-cultural-times-2015.pdf. 
ten üç sektörün sırasıyla görsel sanatlar (6,73 milyon), kitap (3,67 milyon) ve müzik (3,98 milyon) olduğu belirtilmektedir.

Yaratıcı Ekonomi raporları, küresel ölçekteki sektörel gelir ve işgücü istatistiklerini de ortaya koymaktadır. UNESCO çatısı altında yürütülen Aralık 2015 tarihli bir çalışma bulguları mimarlık, gösteri sanatları ve görsel sanatlar, sinema, müzik, basın-yayın, reklamcılık, radyo-televizyon ve dijital oyunlar alanlarında Afrika, Kuzey Amerika, Latin Amerika ve Karayipler, Asya-Pasifik, Avrupa ve Ortadoğu'daki yaratıcı ekonominin güncel durumunu tespit eden bir analiz ortaya koymaktadır. $\mathrm{Bu}$ analize göre ilk sırada Asya-Pasifik bölgesindeki gelirin 743 milyar dolar (toplamın \%3’ü) olarak 12,9 milyon kişilik işgücü (tüm dünyadaki kültür ve yaratıcı endüstriler işgücünün \%43’ü) tarafından üretildiği; bu

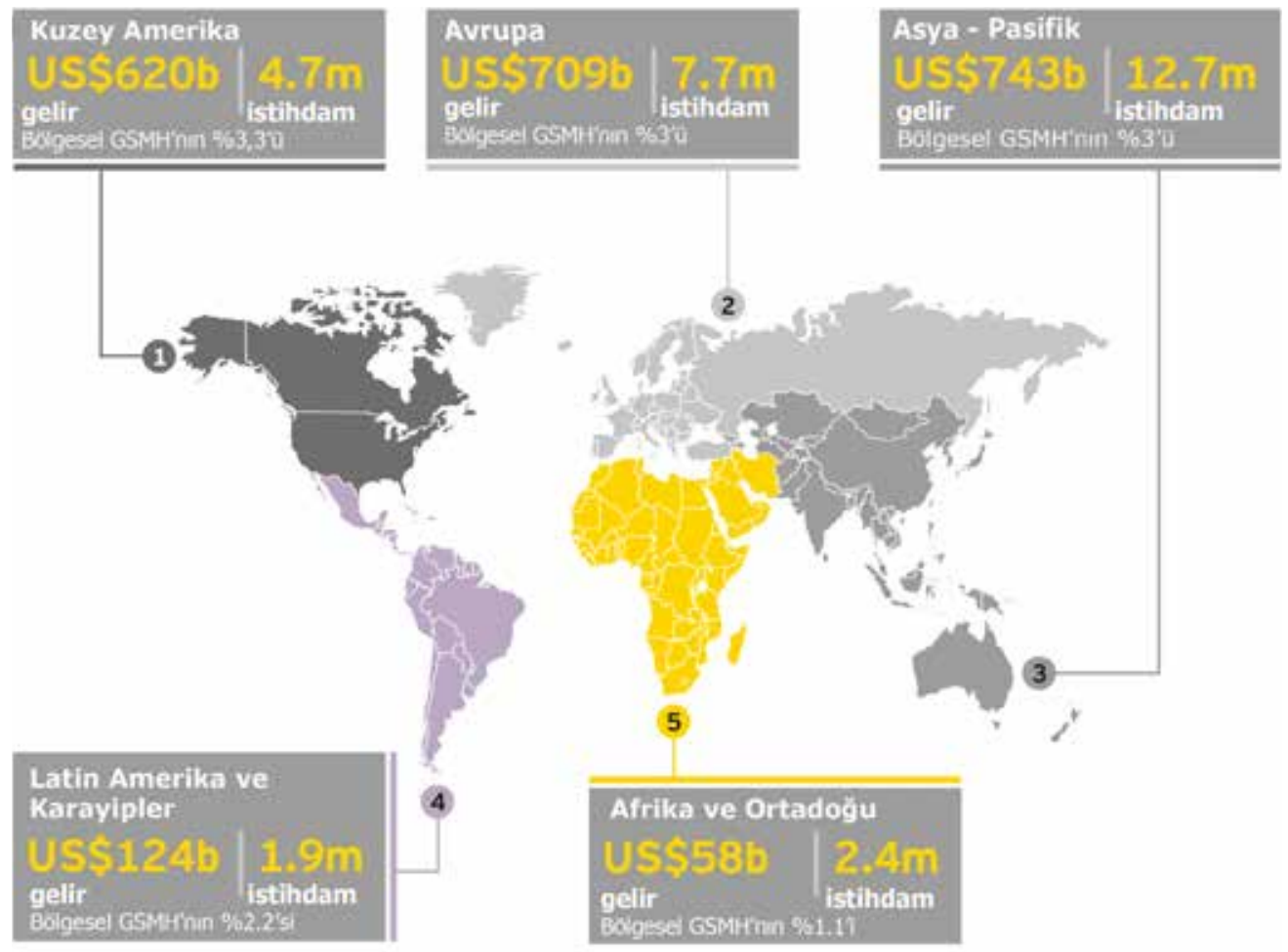

Şekil 1. Dünya ölçeğinde kültür ve yaratıcı endüstrilerden elde edilen gelirler ve işgücü değerleri (B: milyar; M: milyon; tablodaki değerler yaklaşıktır.) Kaynak: UNESCO/EY/CISAC, Cultural Times, 17.

değerleri Avrupa ve Kuzey Amerika kıtalarının izlediği, son olarak Latin Amerika kıtasındaki değerleri ise Afrika'daki sektörel hareketlenmenin takip ettiği tespit edilmiştir (Şekil 1). ${ }^{11}$

11 UNESCO/EY/CISAC, Cultural Times, 17. 
Şekil 1'de verilen değerlerin işaret ettiği bir kritik husus, kültür ve yaratıcı endüstrilerin tüm kıtalarda ölçümlenmekte olduğudur. Kültür ekonomisi kentlerin geleceğe açılan yeni kapısı olarak yaygın kabul görürken, bu yönde kültür politikaları tarif edilmekte, çalışan nitelikli işgücünü artırma stratejileri sorgulanmakta ve uluslarüstü kuruluşlara ait istatistiklerde çarpıcı bir sıraya yükselme yarışında kentsel mekâna türlü yatırımlar yapılmaktadır. Ancak tüm bu sayısal değerleri genel ekonomik ve endüstriyel modellerden ayırmak gereklidir. Özellikle 2013 tarihli Kültür Ekonomisi Raporu'nda vurgulandığı üzere, kültür alanının ekonomik boyutundan öte kültürel çeşitlilik, sosyal içerme ve sürdürülebilir gelişim anlamındaki temel bileşen olması önemlidir. Özellikle kültürel çeşitlilik konusunda, örneğin UNESCO Kültürel İfade Çeşitliliğinin Korunması ve Geliştirilmesi Sözleşmesi'nin ${ }^{12}$ 18. maddesine göre 2010 yılında faaliyete geçen Uluslararası Kültürel Çeşitlilik Fonu (International Fund for Cultural Diversity - IFCD) ile Güney - Güney ve Kuzey - Güney - Güney türü işbirliklerinin ${ }^{13}$ teşvik edilmesi amaçlanmaktadır. Fon kapsamında 40 adet gelişmekte olan ülke projelerine verilen destek ile kültür politikaları, kültür girişimcilerine yönelik kapasite oluşturma, kültür endüstrilerinin haritalanması ve yeni kültür endüstrisi işletme modellerinin yaratımına yönelik fon kullanılması sağlanmıştır. Bu fondan en çok faydalananlar ise \%4,8,1 oranında Afrika ülkelerinde konumlanmakta olup, ağırlıklı olarak sivil toplum kuruluşu olarak faaliyete geçen kültür aktörleri olmuştur. ${ }^{14}$

Bu tür örneklerin, teşviklerin, sonrasındaki gelişmelerin ve kültürel işbirliği hedeflerinin olumlu geri dönüşlerinin ise, değinildiği üzere, salt ekonomik temelde tartışılması doğru olmayacaktır. Nitekim, kültür ve yaratıcı endüstriler para birimi ile ölçülemeyecek faydalar üzerinden kümelendikleri kentlerin kültürel farklılaşan kimliklerine, yerel algıya ve prestij kazanımına yönelik de olumlu katkıları ile yansıma bulmaktadir.

Diğer taraftan, kültür ekonomisine yönelik uluslarüstü kurum ve kuruluşlarca hazırlanan raporlar ${ }^{15}$ temelinde Akdeniz Havzası'na

12 Anılan sözleşme kültür endüstrileri ile ekonomi arasında bir bağ kurarken bu bağın temellendiği mantık, kültürel ifadelerin küresel ölçekteki sirkülasyonunun kültür endüstrileri üzerinden gerçekleşebileceği düşüncesine dayanmaktadır.

13 Uluslararası Kültürel Çeşitlilik Fonu konusunda detaylı bilgi için bknz. United Nations/ UNDP/UNESCO, Creative Economy Report.

14. United Nations/UNDP/UNESCO, Creative Economy Report, 135-36.

15 UNIDO, Mapping of Clusters in Cultural and Creative Industries in the Southern Mediterranean, United Nations Industrial Development Organization Reference Report 1013518 (UNIDO, 2015), erişim tarihi 15 Ekim 2016, http://ec.europa.eu/DocsRoom/ documents/9147/.../1/.../en/.../pdf; Gatti v.d., Jobs for Prosperity: Time for Action in the Middle East and North Africa (Washington, DC: International Bank for Reconstruction and Development /The World Bank, 2013), erişim tarihi 9 Ekim 2016, http://documents. worldbank.org/curated/en/54,0401468051871415/Full-report;WorldBank(CMI/theWorld Bank/EIB/ISESCO),Transforming ArabEconomies:Traveling the Knowledge and Innovation Road (Washington, DC: International Bank for Reconstruction and Development/ 
bakıldığında üç temel tespitte bulunulabilecektir. Buna göre ilk tespit, kültür ekonomisine yönelik analitik bakışın Akdeniz Havzası için herhangi bir Kuzey - Güney bütünlügü içinde kurgulanmamakta olmasıdır. Nitekim İspanya, Fransa, İtalya ve Yunanistan gibi Kuzey Akdeniz ülkeleri ve kentlerindeki kültür ekonomisi, Avrupa Birliği ülkeleri ve kentlerine yönelik analizler ve çıkarımlar kapsamında ve detaylı istatistikî ölçümlemeler üzerinden değerlendirilirken, ${ }^{16}$ Güney Akdeniz ülkelerine yönelik kültür ekonomisi analizlerinin Kuzey Afrika ve/veya Arap ülkeleri arasında ağırlıklı olarak Fas, Tunus, Mısır, Cezayir, Ürdün ve Lübnan gibi ülkeler grubu bütünlüğünde gerçekleştirildiği gözlenmektedir. Akdeniz havzası bütünlüğünde kültür ekonomisini odağa alan karşllaştırmalı analizlerden ziyade, konuya kuzeyde Avrupa Birliği bütünlüğünde, güneyde ise Kuzey Afrika olarak nitelendirilen coğrafyayı paylaşan ülkeler temelinde bakılmakta ve genel sektörel gelişmelerin nabzı tutulmaya çalışılmaktadır. 2010 sonunda Arap Baharı olarak yaşanan gelişmelerin ortaya çıkmasından önceki kimi çalışmalarda Cezayir, Mısır, Ürdün, Lübnan, Fas, Filistin, Suriye ve Tunus'un bir bütün olarak ele alınmasının Arap ülkelerindeki kültür politikalarının oluşumu için önemli olduğunu öne sürülürken, ${ }^{17}$ daha güncel başka çalışmalar ise adı geçen ülkelere ait kültür ve yaratıcı endüstrilerdeki gelişmeleri ve oluşturulması gereken politikaları Afrika kıtası bütünlüğünde ele almaktadır. UNCTAD bünyesinde Yaratıcı Afrika İnisiyatifinin (Creative Africa Initiative) oluşturulmasının ardından Afrika'da Yaratıcı Ekonomiler konulu analizlerin ve Avrupa'daki Kültür Gözlem Komisyonu (Culturewatch Europe) ${ }^{18}$ benzeri bir oluşum olarak Artwatch Africa ${ }^{19}$ adlı sektörel gözlem ve tespit amaçlı oluşumlar buna örnek olarak gösterilebilecektir.

The World Bank, 2013), erişim tarihi 19 Ekim 2016, https://openknowledge.worldbank. org/bitstream/handle/10986/16750/82736oESWov1oPooBox379869BooPUBLICo. pdf? sequence $=1 \&$ is Allowed $=y$.

16 Avrupa kentlerinde yaratıcı ekonominin genel ekonomi içerisindeki durumunun tespitine ilişkin ilk kapsamlı çalışma 2006 yılında yayımlanan "Avrupa'da Yaratıcı Ekonomi” raporu olmuştur. KEA (Kern European Affairs), The Economy of Culture in Europe (Brüksel: European Commission/KEA, 2006). Anılan raporda 25 Avrupa ülkesinin 3-basamaklı sektörel veri tabanı bazındaki verilerine göre kültür ve yaratıcı endüstrilerin Avrupa kıtasındaki temel ekonomik faktör olduğu tespit edilmiştir.

17 Ineke van Hamersveld, Cultural Policies in Algeria, Egypt, Jordan, Lebanon, Morocco, Palestine, Syria and Tunisia: An Introduction (Amsterdam: Avrupa Boekmanstudies, Culture Resource, Al Mawred Al Thaqafy and European Cultural Foundation, 2010).

18 Avrupa Birliği bünyesindeki Kültür Gözlem Komisyonu (CultureWatch Europe: Cultural Governance Observatory) ve Açık Kültür Envanteri (Open Compendium) türü platformlar kültür ve yaratıcı endüstri sektörlerinde faaliyet gösteren kültür aktörlerinin ve söz konusu kültür üreticilerinin gereksinim duyduğu ağın oluşumu amaçlı olarak faaliyet göstermektedir.

19 Afrika'da Arterial Network çatısı altında yer alan Artwatch Africa'nın amacı bir yandan kültür aktörlerinin ifade özgürlüğü konularında, diğer yandan altyapı ve kaynaklara erişim, yasal destek mekanizmaları, telif hakları, kültürel çeşitlilik ve formel ve enformel eğitim konularında tüm sanatçıların eşit düzeyde erişebilir olacağı bir ağ oluşturmaktır. Detaylı bilgi için bkz. http://www.arterialnetwork.org/artwatch. 
İkinci tespit, kültür ekonomisi çalışmalarının ölçeğine ve kapsamına dair farklılaşmalara ilişkindir. Avrupa Birliği üyesi ülkelerdeki araştırmalarda Avrupa İstatistik Bürosu (EUROSTAT) veri tabanı temelinde NUTS ${ }^{20}$ Düzey 2 sinıflamaları gibi bölgesel istatistiklerin ${ }^{21}$ yanı sıra kentler özelinde spesifik kültür envanteri çalışmalarında kıyaslamalı analitik sorgulamalar yapıldığı ve kültür ekonomisinin mevcut durumunun tespit edilmeye çalışıldığı söylenebilecektir. Bu istatistiklerde kültür ve yaratıcı endüstrilerin ağırlıklı olarak formel sektörler üzerinden hesaplandığı belirtilmektedir. Kuzey Akdeniz'de kültür ekonomisine ilişkin çok sayıda kentsel ölçekli araştırma mevcuttur. Örneğin Barselona, ait olduğu İspanya sınırlarını aşarak özellikle kültür turizminden yaratıcı turizme geçişin temsilcisi bir kent olarak anılırken, Olimpiyatlar sonrasındaki gelişmeleri "Barselona Modeli” olarak çok sayıda çalışmaya ve uygulamaya örnek teşkil eder. ${ }^{22}$ Yaratıcı Ekonomi raporlarında adı geçen $\mathrm{AB}$ dışı diğer ülkelere ilişkin veri tabanları ise ülke bütünü için aktarılırken, Akdeniz ülkelerinin dâhil olduğu Afrika kıtasına ilişkin olarak kültür ekonomisinin ağırlıklı olarak enformel sektörler üzerinden faaliyet gösterdiği gözlenmektedir. ${ }^{23}$ Bir Güney Akdeniz ülkesi olarak Fas'taki kültür ve yaratıcı endüstrilerin faaliyetlerine ilişkin envanter için kültür ekonomisi veri bankası oluşturma ve haritalandırma çalışmalarının ülke ve kent yönetimleri düzeyinde yürütülmediği, bu konuda münferit olarak sanat kolektiflerinin UNESCO destekli olarak kurgulanan projelerde aktif olarak çalışarak kültür ekonomisine ilişkin mevcut durumu belgelendirdikleri ifade edilmektedir. ${ }^{24}$ Münferit olarak

20 Avrupa Birliği (AB) İstatistik Bürosu (EUROSTAT) tarafından AB'de üretilecek bölgesel istatistiklerde belli bir yapı oluşturmak için İstatistikî Bölge Birimleri Sınıflaması (IBBS) - Nomenclature of Territorial Units for Statistics (NUTS) geliştirilmiştir. Yaratıcı ekonomilerdeki işgücü ölçümlemelerinde ağırlıklı olarak NUTS sınıflamasının temel alındığı söylenebilecektir. Türkiye'de de aynı sınıflama sistemi kullanılmaktadır.

21 Antonio Russo ve Alan Quagliari, Creative Workforce in Europe: Territorial Patterns and Effects (Barselona: ERSA Congress, 2011), erişim tarihi 11 Ekim 2016, http://www-sre. wu.ac.at/ersa/ersaconfs/ersa11/e110830aFinalooo64.pdf.

22 Francisco Javier Monclús, “Barcelona's planning strategies: from 'Paris of the South' to the 'Capital of West Mediterranean'”, GeoJournal 51 (2001): 57-63; Michael Parkinson, Barcelona, ESPON 2013 Scientific Report (EU and ESPON, 2013), erişim tarihi 11 Ekim 2016, https://www.liverpool.ac.uk/media/livacuk/publicpolicypractice/euconference/ Barcelona,Case,Study.pdf.

23 UNESCO/EY/CISAC, Cultural Times; Najib Harabi, Creative Industries: Case Studies from Arab Countries (Munich Personal RePEc Archive-MPRA, 20o9), erişim tarihi 11 Ekim 2016, http://mpra.ub.uni-muenchen.de/15628/; UNCTAD, The Creative Economy Report 2010. Creative Economy: A Feasible Development Option, UNCTAD/DITC/TAB/2010/3 (Cenevre: United Nations: 2010), 54, erişim tarihi 11 Ekim 2016, http://www.unctad.org/ en/docs/ditctab20103_en.pdf.

24. Mehdi Azdem, Fabrique Culturelle des anciens abattoirs de Casablanca, yayımlanmamış sunum, İzmir Akdeniz Akademisi Kültür Platformu Toplantıları, 25 Eylül 2016. Fas’ta faaliyet gösteren kültür ve yaratıcı endüstrilerin haritalandırılma çalışmalarına http://www.artmap.ma adresinden ulaşılabilir. Anılan haritalama çalışmasında Kazablanka'daki sanatçlların tespiti amaçlı başlayan ve dört sene boyunca envanteri dökülen 18 ayrı sektörel analizinin yanı sıra, sanatçılara yönelik GZTF analizlerinin de 
Akdeniz kentlerinde kültür ekonomisine odaklanan yerel ölçekli çalışmalar bulunup bulunmadığının tespiti ise oldukça sıkıntılıdır. Örneğin Harabi, Fas, Tunus, Mısır, Ürdün ve Lübnan'da kitap yayımı, müzik ve ses kaydı, film yapımı ve yazılım sektörleri olarak belirlediği dört kültür endüstrisi sektöründeki araştırmalarında sektörlerin ekonomik performanslarının kıyaslamalı olarak ölçümlerini gerçekleştirmiş ve temel veri tabanı olarak Dünya Fikri Mülkiyet Örgütü (World Intellectural Property Organization - WIPO) tarafından hazırlanan uluslararası araştırma raporlarını kullanmıştır. ${ }^{25}$ Sonuç itibariyle, kültür ekonomisi durum tespitlerinin ülkesel ölçekten ziyade, yerel ölçekte detaylı veri sunumuna ilişkin sıkıntıların Güney Akdeniz ülkeleri için daha ciddi boyutta olduğu öne sürülebilecektir.

Son tespit ise kültür ve yaratıcı sektörlerdeki mekânsal kümelenme çalışmalarına ilişkindir. Güney Akdeniz ülkelerinde gerçekleştirilen kültür ekonomisi çalışmalarında kültür ve yaratıcı endüstrilerin mekânsal kümelenme eğilimlerine ilişkin olarak Birleşmiş Milletler Endüstriyel Kalkınma Örgütü (United Nations Industrial Development Organization - UNIDO) uzmanlarınca Mayıs-Ekim 2014 tarihleri arasında gerçekleştirilen AB destekli bir çalışma bu anlamda önemli bir kaynak teşkil eder. ${ }^{26}$ Bu çalışmaya bakıldığında, sektörlerin yine ülkeler bazında ayrışmakla beraber, Güney Akdeniz ülkeleri bütünlüğündeki kümelenme eğilimlerine temellendiği anlaşılmaktadır. Anılan çalışmada, kültür ve yaratıcı endüstrilerdeki farklı alt sektörlerin ağırlıklı olarak Fas ve Mısır'da kümelenme gösterdiği tespit edilmiştir (Şekil 2). Kültür ve yaratıcı sektörlerin ayrı ayrı alt disiplinler özelinde ne tür bir gelişim içerisinde olduğundan bağımsız olarak değerlendirilecek olursa, Akdeniz havzası içerisinde kuzeyde daha kentsel/yerel ağırlıklı ve münferit gelişmeler ön plana çıkarken, güneyde Akdeniz ülkelerinin ortak bir paydada ele alındığı ve kentsel ölçekten ziyade, bölgesel rekabet-edebilirlik stratejilerinin tartışıldığı öne sürülebilecektir.

Bütün bu tespitlerin farkında olunması, kültür ekonomisi açısından Akdeniz kentleri arasında nasıl bir ilişkiler ağı kurulabileceğine yönelik sorgulamaları da yönlendirici olacaktır. Türkiye'deki Akdeniz kentlerinin bu ağ içerisindeki yerleri de aynı çerçevede tartışılmalıdır.

\section{Akdeniz Kentler Ağında Kültür Ekonomisi ve İzmir}

Akdeniz kentleri bütünlüğü içinde Türkiye kentlerine bakılacak olursa, İzmir'de 2009 sonrasında atılan adımlar ve ortaya konulan stratejiler önemlidir. ${ }^{27}$ Türkiye'de kültür ekonomisi ve politikaları alanındaki

yapıldı̆̆ı belirtilmektedir.

25 Harabi, Creative Industries.

26 UNIDO, Mapping of Clusters.

27 Türkiye'de İstanbul, Ankara ve İzmir'de kültür ekonomisi ve kültür altyapısı envanteri ve kültür politikaları oluşturma yönünde 2010 sonrasında önemli çalışmalar yapılmıştır. 


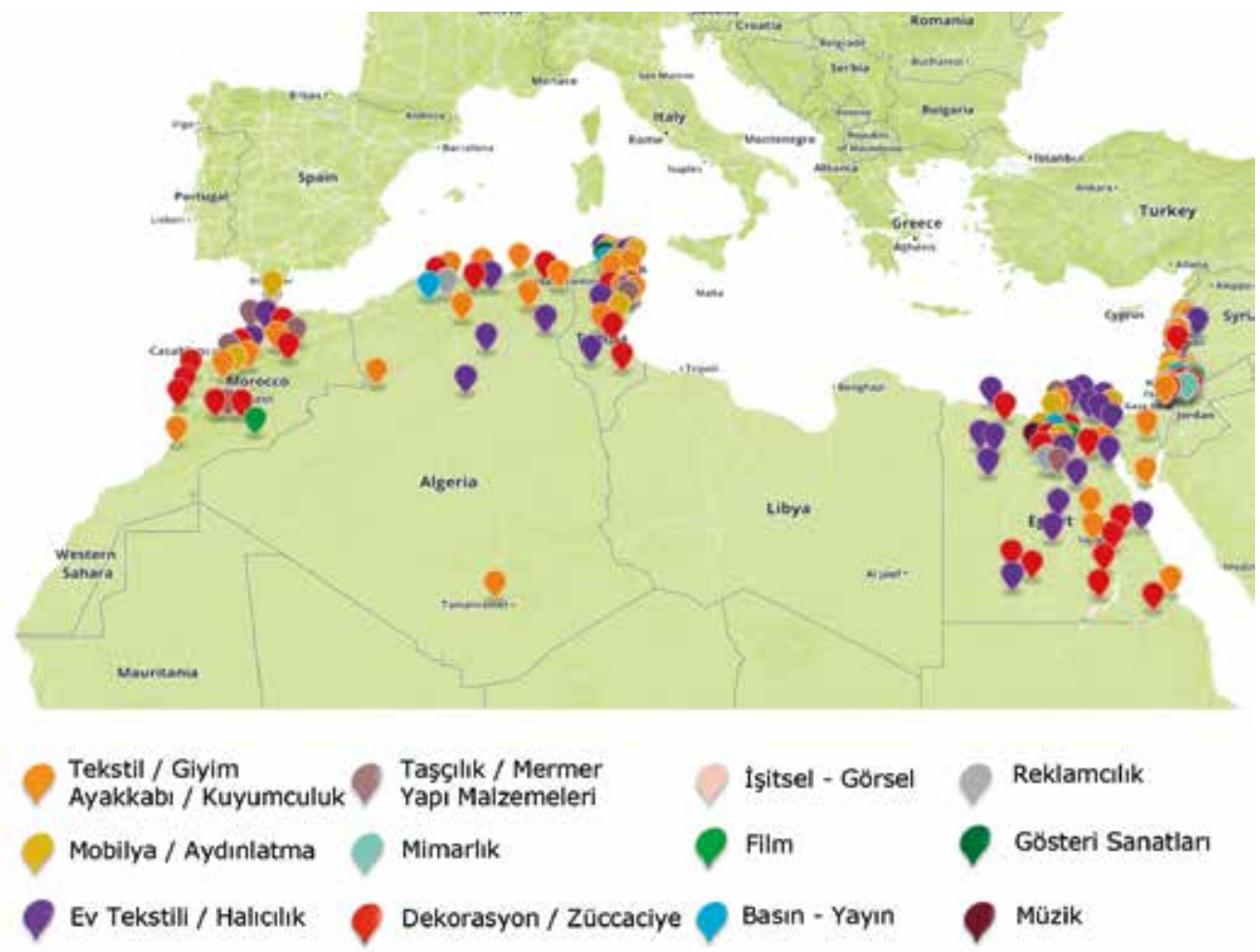

Şekil 2. Güney Akdeniz'de Kültür ve Yaratıcı Sektörlere ilişkin Mekânsal Kümelenme haritası. Kaynak: UNIDO, Mapping of Clusters, 6.

gelişmeler kapsamında İzmir Kültür Çalıştayı'nın ${ }^{28}$ (2009) ardından İzmir Akdeniz Akademisi'nin kurulması ve sonrasında İzmir Kültür Ekonomisi Çalıştayı'nın da ilk olarak İzmir'de gerçekleştirilerek İzmir 2014-2023 Bölge Plan ${ }^{29}$ kapsamında İzmir Kültür Ekonomisi Gelişme Stratejisi: İzmir 2012 Kültür Ekonomisi ve Kültür Altyapısı Envanteri ${ }^{30}$

Türkiye'deki kültür ve yaratıcı sektörlerin durumuna ilișkin tespit ve değerlendirmeler diğer kentlerde yapılacak çalışmalara örnek teşkil edebilecektir. İstanbul'daki çalışmalar için bkz. Asu Aksoy ve Zeynep Enlil, Kültür Ekonomisi Envanteri İstanbul 2010 (İstanbul: İstanbul Bilgi Üniversitesi Yayınları, 2011); Ankara'daki çalışmalar için bkz. AKA (Ankara Kalkınma Ajansı), Ankara Kültür Mirası ve Kültür Ekonomisi Envanteri (Ankara: Ankara Kalkınma Ajans, 2011), erişim tarihi 15 Ekim 2016, http://www.ankaraka.org.tr/tr/data. asp?id=1318.

28 İZKA (İzmir Kalkınma Ajansı), İzmir 2014-2023 Bölge Planı (İzmir: İzmir Kalkınma Ajansl, 2013), erişim tarihi 11 Ekim 2016, http://www.izka.org.tr/planlama/bolge-plani-dokumanlari/2014,2023bolgeplani. Detaylı bilgi için bkz. http://www.izmirelele.com/ Extras/file/kulturcalistayi.pdf.

29 Detaylı bilgi için bkz. http://www.izka.org.tr/planlama/bolge-plani-dokumanlari/ 2014,2023bolgeplani/

30 Dündar v.d., İzmir Kültür Ekonomisi Gelişme Stratejisi: İzmir 2012 Kültür Ekonomisi ve Kültür Altyapısı Envanteri, İZKA İzmir Bölge Planı 2014-2O23 Bölgesel Analizleri (İzmir: 
oluşturulması bu alandaki önemli kırılma noktalarını oluşturur. İzmir için belirlenen kültür-sanat ve tasarım metropolü ve Akdeniz Kentler Ağı'nın etkin üyesi olma yönündeki hedeflerin bugün geldiği noktada, kültür ekonomisine ilişkin olarak kapsamlı araştırma ve analizlerde İzmir'in kültür ekonomisi açısından İstanbul ve Ankara ile birlikte ülkenin önde gelen kültürel üretim alanlarından birini oluşturmakta olduğu açıktır. İzmir'i ülkenin diğer iki gelişmiş kentinden ayıran özelliklerinden biri Akdeniz Kentler Ağı'na üye olması ise, bir diğeri 2016 yılında Kültür için Gündem 21 - Pilot Kenti ${ }^{31}$ seçilmiş olmasıdır.

Ancak, tıpkı Güney Akdeniz ülkelerindeki istatistikî veri oluşturma sıkıntısı gibi, Türkiye'de de ülke genelinde sadece kültür ekonomisinin boyutuna ilişkin değerlendirmeler (istihdam, üretim, katma değer, yatırım vb.) yapılabilmekte, bölgesel düzeyde bir kültür ekonomisi verisi üretilememektedir. Kültür ve yaratıcı endüstri sektörlerine ilişkin TÜİK tarafından paylaşılan en son veriler 2002 yılına aittir. Bu veriler temelinde, Türkiye'de kültür ekonomisinde çalışanların \%6,3’ünün İzmir'de, \%26,2'sini İstanbul'da ve \%13,8'inin de Ankara'da istihdam edildiği ölçümlenmiştir. Dolayısıyla, Türkiye'deki kültür ekonomisi istihdamının neredeyse yarısı bu üç metropol şehir tarafından sağlanmaktadır. ${ }^{32}$ Kültür ekonomisinin nasıl kümelendiğine ilişkin olarak gerçekleştirilen Üç Yıldız Analizi ${ }^{33}$ sonuçlarına göre de İzmir'de dört sektörün olgun küme olarak kabul edilebileceği anlaşılmaktadır. Söz konusu sektörler 74.20 kodlu "Mimarlık, mühendislik ve ilgili teknik danışmanlık faaliyetleri", 74.87 kodlu "Başka yerde sınıflandırılmamış diğer iş faaliyetleri" ${ }^{34} 72.21$ kodlu "Bilgisayar yazılımı üretim hizmetleri" ve 80.42 kodlu "Yetişkinlerin eğitilmesi ve başka yerde sınıflandırılmamış diğer eğitim

IZKA, 2013), erişim tarihi 11 Ekim 2016, http://www.izmiriplanliyorum.org/static/upload/ file/izmir_kultur_ekonomisi_envanteri_ve_kultur_ekonomisi_stratejisi_projesi.pdf.

31 2004 yılında UCLG Kültür Komitesi (Birleşmiş Kentler ve Yerel Yönetimler Teşkilatı/ United Cities and Local Governments) tarafından kabul edilen Kültür için Gündem 21 (Agenda 21 for Culture) ise yerel yönetimlerin sürdürülebilir kalkınma amacıyla kültür alanında gelişime dayalı ilke ve taahhütlerini belirleyen kültür alanındaki uluslararası çerçeve politikalara önemli bir örnektir. Daha detaylı bilgi için bkz. http://www. agenda21culture.net/index.php/docman/-1/393-zzculture4pillarsden/file.

32 Dündar v.d., İzmir Kültür Ekonomisi Gelişme Stratejisi, 36.

33 Üç Yıldız Analizi, Avrupa Komisyonu'nca finanse edilen European Cluster Observatory platformu tarafından geliștirilen bir tekniktir. "İstihdamın göreli oranlarının bir eşik değer ile kıyaslanarak değerlendirilmesi” esasına dayanmaktadır. Söz konusu analiz yönteminde "büyüklük, baskınlık ve uzmanlık" olmak üzere üç temel gösterge bulunmaktadır. Her bir gösterge için bir eşik değer belirlenmekte ve eğer herhangi bir faaliyet alanı için hesaplanan değer daha önceden belirlenmiş olan eşik değeri aşarsa, ilgili faaliyet bu kriterden bir yıldız almaktadır. Yani tek bir göstergenin eşik değerini aşan faaliyet bir yıldız, iki göstergenin eşik değerini aşan faaliyet iki yıldız, üç göstergenin de eşik değerini aşan faaliyet üç yıldız almış olarak nitelendirilmekte ve üç yıldız alan faaliyetin "o bölgede kümelenme" gösterdiği kabul edilmektedir. Detaylı bilgi için bkz. Dündar v.d., İzmir Kültür Ekonomisi Gelişme Stratejisi, 4.0.

34. Bu kod, iç dekorasyon, diğer kişisel eşyalar ve ev içi eşyalarla ilgili moda tasarımı, grafik tasarımcıların faaliyetleri, iç dekorasyon tasarımcılarının faaliyetleri, fuar, sergi ve kongre organizatörlerinin faaliyetleri, stant tasarımcılarının faaliyetleri vb. faaliyetleri kapsamaktadır. 
faaliyetleri" ${ }^{35}$ olarak tespit edilmiştir. Özetlemek gerekirse, İzmir'de mimarlık, tasarım, kültür eğitimi ve yazılım sektörlerinde kümelenme olduğu söylenebilecektir. ${ }^{36}$

Kuzey Akdeniz ülkelerine bakıldığında, İtalya, Fransa ve İspanya gibi gelişmiş ülke örneklerinin kültür ekonomisi açısından yönlendirici örnek teşkil ettiği, hatta Barselona yaratıcı kent modelinin İzmir'in geleceği için sıklıkla örnek gösterildiği söylenebilecektir. Güney Akdeniz ülkelerine bakıldığında ise, anılan coğrafyada kültür endüstrilerinin enformel niteliği ve resmi veri oluşumundaki slkıntılara rağmen, mekânsal kümelenme gösteren sektörlerin ağırlıklı olarak tekstil ve dekorasyon alanlarında yoğunlaştığı (Şekil 2) görülmektedir. Özellikle Mısır, Fas ve Tunus'ta yığılma gösteren kültür bölgelerine ilişkin deneyim Akdeniz Kentler Ağının etkin bir üyesi olma hedefi taşıyan İzmir için dikkate alınabilecektir. İzmir kentindeki kültür ekonomisi deneyimi ise, gerek kültür ve yaratıcı endüstri sektörlerine yönelik ekonomik analizler açısından, gerekse İzmir Akdeniz Akademisi ile başlayıp Kültür için Gündem 21 - Pilot Kenti olmaya giden süreçte kültür alanındaki yerel yönetim yapılanma yöntemi açısından Güney Akdeniz kentleri için örnek teşkil edebilecektir.

Sonuç itibariyle, daha önce değinildiği üzere, kültür ve kalkınma arasındaki ilişki salt ekonomik hedefler üzerinden değerlendirilemez. Kültür ve yaratıcılığın ekonomik boyutundan öte, kültürlerarası işbirliği, yerel kimlik ve yaşanabilirlik gibi görece ölçülemeyen boyutları açısından çok farklı katkılar sunduğu açıktır. Akdeniz kentleri arasında kurulabilecek ilişkilerin ise bu açıdan yeniden değerlendirilmesi ve kültür ve yaratıcı endüstriler alanındaki her deneyimin yerel özellikler bozulmadan özgün birer örnek olarak ele alınarak ilişkilendirilmesi mümkündür. Akdeniz havzasına bu perspektiften bakılmasının ise yerel yönelimlerin, değerlerin, sınırlayıcı faktörlerin ve enerjilerin verimli bir şekilde kültür politika ve stratejilerine dönüştürülmesini sağlayabileceği açıktır.

35 Yetişkinlerin eğitimini, yani, düzenli eğitim ve üniversite sistemine dâhil olmayan kişilere yönelik yapılan eğitimi kapsamaktadır.

36 Dündar v.d., İzmir Kültür Ekonomisi Gelişme Stratejisi. 


\section{Kaynakça}

Adorno, Theodor W. Kültür Endüstrisi, Kültür Yönetimi. Çeviren M. Tüzel, N. Ülner, E. Gen. İstanbul: İletişim, 2014.

AKA (Ankara Kalkınma Ajansı). Kültür Mirası ve Kültür Ekonomisi Envanteri. Ankara: Ankara Kalkınma Ajansı, 2011. Erişim tarihi 15 Ekim 2016, http:// www.ankaraka.org.tr/tr/data.asp?id=1318.

Aksoy, Asu ve Zeynep Enlil. Kültür Ekonomisi Envanteri İstanbul 201O. İstanbul: İstanbul Bilgi Üniversitesi Yayınları, 2011.

Azdem, Mehdi. Fabrique Culturelle des anciens abattoirs de Casablanca. Yayımlanmamış sunum, İzmir Akdeniz Akademisi Kültür Platformu Toplantıları, 25 Eylül 2016.

Dündar, Şebnem Gökçen. "Kültür Endüstrisi ve Bölgesel Kalkınma”. Bölgesel Kalkınmada Yeni Trendler içinde, derleyen Z. Mızrak ve B. Mercan, 247-272. Konya: Çizgi Kitabevi, 2016.

Dündar, Şebnem, Neşe Kumral, Zehra Ersoy, Mehmet Güçlü, Burcu Türkcan, İbrahim Alpaslan, Gülçin Gürel, Deniz Coşkun Satırcı, Gökçe Sanul. İzmir Kültür Ekonomisi Gelişme Stratejisi: İzmir 2012 Kültür Ekonomisi ve Kültür Altyapısı Envanteri. İZKA İzmir Bölge Planı 2014-2O23 Bölgesel Analizleri, 2013. Erişim tarihi 11 Ekim 2016, http://www.izmiriplanliyorum.org/static/ upload/file/izmir_kultur_ekonomisi_envanteri_ve_kultur_ekonomisi_ stratejisi_projesi.pdf.

Florida, Richard. The Rise of the Creative Class. New York, NY: Basic Books, 2002.

Florida, Richard. "Cities and the Creative Class". City and Community 2:1 (2003): 3-19. Erişim tarihi 11 Ekim 2016, http://isites.harvard.edu/fs/docs/icb. topic233886.files/April_8/Florida_Cities.pdf.

Gabe, Todd, Richard Florida ve Charlotta Mellander. "The Creative Class and the Crisis". Cambridge Journal of Regions, Economy, and Society 6 (2013): 37-53.

Gatti, Roberta, Mateo Morgandi, Rebecca Grun, Stefanie Brodmann, Diego Angel-Urdinola, Juan Manuel Moreno, Daniela Marotta, Marc Schiffbauer ve Elizabeth Mata Lorenzo. Jobs for Prosperity: Time for Action in the Middle East and North Africa. Washington DC: International Bank for Reconstruction and Development, the World Bank, 2013. Erişim tarihi 9 Ekim 2016, http:// documents.worldbank.org/curated/en/540401468051871415/Full-report.

Harabi, Najib. Creative Industries: Case Studies from Arab Countries. Munich Personal RePEc Archive -MPRA, 2009. Erișim tarihi 13 Ekim 2016, http:// mpra.ub.uni-muenchen.de/15628.

İZKA. İzmir 2014-2023 Bölge Planı. İzmir: İzmir Kalkınma Ajansı, 2013. Erişim tarihi 15 Ekim 2016, http://www.izka.org.tr/planlama/bolge-planidokumanlari/2014,2023bolgeplani.

KEA (Kern European Affairs). The Economy of Culture in Europe. Brüksel: European Commission/KEA: 2006. 
Mitchell, Ritva. "Nordic and European cultural policies". The Nordic Cultural Model içinde, derleyen P. Duelund, 437-478. Kopenhag: Nordic Cultural Institute, 2003.

Monclús, Francisco Javier. "Barcelona's planning strategies: from 'Paris of the South' to the 'Capital of West Mediterranean'”. GeoJournal 51 (2001): 57-63.

Parkinson, Michael. Barcelona. ESPON 2013 Scientific Report (2013). Erişim tarihi 11 Ekim 2016, https://www.liverpool.ac.uk/media/livacuk/ publicpolicypractice/euconference/Barcelona,Case,Study.pdf.

Power, Dominic ve Tobias Nielsén. Priority Sector Report: Creative and Cultural Industries. Preliminary Version. Brüksel: European Cluster Observatory, 2010.

Power, Dominic. Priority Sector Report. Creative and Cultural Industries. Europa Innova Paper n.16. Lüksemburg: European Commission, European Cluster Observatory, 2011.

Russo, Antonio ve Alan Quagliari. Creative Workforce in Europe: Territorial Patterns and Effects. Barselona: ERSA Congress, 2011. Erissim tarihi 11 Ekim 2016, http://www-sre.wu.ac.at/ersa/ersaconfs/ersa11/e110830aFinalooo64.pdf.

UNCTAD. The Creative Economy Report 2010. Creative Economy: A Feasible Development Option. UNCTAD/DITC/TAB/2010/3. Cenevre: United Nations: 2010. Erişim tarihi 11 Ekim 2016, http://www.unctad.org/en/docs/ditctab20103_en.pdf.

UNESCO/EY/CISAC. Cultural Times: The First Global Map of Cultural and Creative Industries. EY, 2015. Erişim tarihi 11 Ekim 2016, http://www.ey.com/Publication/ vwLUAssets/ey-cultural-times-2015/\$FILE/ey-cultural-times-2015.pdf.

UNIDO. Mapping of Clusters in Cultural and Creative Industries in the Southern Mediterranean. United Nations Industrial Development Organization Reference Report 1013518. UNIDO, 2015. Erişim tarihi 15 Ekim 2016, ec.europa.eu/DocsRoom/documents/9147/.../1/.../en/.../pdf.

United Nations/UNDP/UNESCO. Creative Economy Report 2013 Special Edition: Widening Local Development Pathways. New York, NY: United Nations Development Program, 2013. Erişim tarihi 9 Ekim 2016, http://www.unesco. org/culture/pdf/creative-economy-report-2013.pdf; http://academy.ssc.undp. org/creative-economy-report-2013.

Van Hamersveld, Ineke. Cultural Policies in Algeria, Egypt, Jordan, Lebanon, Morocco, Palestine, Syria and Tunisia: An Introduction. Amsterdam: Avrupa Boekmanstudies, Culture Resource (Al Mawred Al Thaqafy) and European Cultural Foundation, 2010.

World Bank (CMI/the World Bank/EIB/ISESCO). Transforming Arab Economies: Traveling the Knowledge and Innovation Road. Washington, DC: International Bank for Reconstruction and Development/The World Bank, 2013. Erişim tarihi 16 Ekim 2016, https://openknowledge.worldbank.org/ bitstream/handle/10986/1675o/82736oESWov10PooBox379869BooPUBLICo. pdf? sequence $=1 \&$ isAllowed $=\mathrm{y}$. 